\title{
Understanding Socio-Ecological Vulnerability to Climatic Change through a Trajectories of Change Approach: A Case Study from an Indigenous Community in Panama
}

\author{
AVITAL LI \\ Department of Geography, McGill University. Montreal, Quebec, Canada \\ JAMES FORD \\ Priestley International Centre for Climate, University of Leeds, Leeds, United Kingdom
}

(Manuscript received 14 September 2018, in final form 3 February 2019)

\begin{abstract}
This paper identifies and characterizes vulnerability to climatic change in the Ngöbe-Buglé Indigenous community of Playitas, Panama, using a "trajectories of change" approach. Playitas is a community composed of swidden forest farmers that is undergoing rapid rates of change as a result of demographic shifts, regional development, and climate change. Working in collaboration with a community organization, various methods were used to identify and characterize livelihoods, social-ecological dynamics, environmental change, and behavioral responses to change, with the aim of informing future planning in the community. Qualitative methods included semistructured interviews $(n=26)$, community workshops, and participant observation. Causal-loop diagrams based on field data and the perceptions of community members were created to model trajectories of change. The research reveals that change is driven by both internal and external factors and that the responses of community members create both reinforcing and balancing feedback loops that overall generate increased stress in agricultural systems, social structures, and environmental components. Although community members historically relied on social relationships, Indigenous knowledge, and remoteness as sources of resilience to external disturbances, climate change is acting as a "multiplier" of their existing vulnerabilities and is undermining their capacity to adapt to current and future climatic changes.
\end{abstract}

\section{Introduction}

Climate change is one of the main threats facing humanity in the twenty-first century, with certain populations and ecosystems being more vulnerable to its impacts than others (IPCC 2018). Central America and the Caribbean-region countries been identified as a "hot spot" region that will experience considerable climate impacts, including projected increases in the magnitude and frequency of extreme weather events, changes in precipitation patterns, higher temperatures, increases in the number of dry days, and sea level rise (IPCC 2014, 2018). According to the Notre Dame Global Adaptation Initiative (ND-GAIN) vulnerability index, all Central American countries are underprepared or poorly prepared to manage these impacts (https:/gain.nd.edu/ our-work/country-index/rankings/).

Corresponding author: Avital Li, avital.li@mail.mcgill.ca
Marginalized and disadvantaged groups are disproportionally vulnerable to climate impacts, particularly Indigenous peoples, who often experience high levels of poverty, high dependency on renewable resources, lack of recognition of their rights and institutions, and ongoing colonization (Ford et al. 2012; ILO 2017). Climate change is expected to act as a "multiplier" to these existing disadvantages and threaten the basis of Indigenous culture, institutions, and practices (Ford et al. 2016; Green and Raygorodetsky 2010; Maru et al. 2014; Mearns and Norton 2010). Despite the importance of climate change to Indigenous peoples' livelihoods and their considerable knowledge on ecosystems and natural processes, they have until recently been excluded from debates on climate policy across scales (Belfer et al. 2019; Ford et al. 2016; ILO 2017; Maldonado et al. 2016). The study of climate vulnerability and environmental hazards, for example, has been dominated by a technocratic perspective of environmental change, which stresses 
the biophysical drivers of and solutions to vulnerability (Adger 2006; Castree et al. 2014; McDowell et al. 2016; O'Brien et al. 2007; Turner 2010; Turner et al. 2003). Such work has largely overlooked Indigenous knowledge, perceiving it as "anecdotal" and "nonscientific" (Castree et al. 2014; Ford et al. 2016; Ford et al. 2012). In the past decade, however, there has been growing attention to the importance of Indigenous knowledge in documenting climate impacts (Savo et al. 2016) and increased understanding of how Indigenous communities perceive, conceptualize, and respond to environmental change (Green and Raygorodetsky 2010; Maldonado et al. 2016; Nakashima et al. 2012; Nyong et al. 2007; Pearce et al. 2018; Pearce et al. 2015). Herein, Indigenous knowledge can be defined as the "cumulative body of knowledge, practice and belief, evolving by adaptive processes and handed down through generations by cultural transmission, about the relationship of living beings (including humans) with one another and with their environment" (Díaz et al. 2015a, p. 13) (see also Díaz et al. 2015b).

Scholarship examining Indigenous societies interacting with climatic changes draws upon a number of intellectual traditions, including vulnerability, sustainability science, resilience, and political ecology, each offering unique insights on the dynamics of social-ecological interactions. This work emphasizes the need for integrated assessments, collaborations between academics and practitioners, and iterative multistakeholder assessments (Cutter et al. 2008; GIZ 2014; Kates et al. 2001; Plummer 2009; Turner et al. 2003; Wise et al. 2014). The complex nature of social-ecological interactions challenges standard linear modes of thinking and requires the use of systems thinking, which is better able to approach complex contexts in which there is limited certainty, multiple stakeholders, low predictability, and ongoing dynamic change (BeLue et al. 2012; Hjorth and Bagheri 2006; Purnomo et al. 2004; Turner et al. 2003; Wise et al. 2014).

The concept of pathways of change and response, or "trajectories of change," has emerged both as a useful systems thinking heuristic to evaluate context-specific causes of vulnerability and resilience and to identify robust, long-term, and feasible adaptation strategies that address underlying drivers of vulnerability (Fazey et al. 2011; Wise et al. 2014). Fazey et al. (2011) define a trajectory of change as "a dynamic process of individual, group and/or societal responses to change which create further change and responses with outcomes that reflect the cumulative properties of that process" (p. 1276). Understanding pathways of change develops knowledge of context-specific, long-term effects of social-ecological interactions that facilitates the identification of adaptive strategies that are both feasible and desirable for the community in question (Fazey et al. 2011).
This study identifies, characterizes, and examines trajectories of change in the Ngöbe-Buglé Indigenous community of Playitas, a neighborhood in Panama's Veraguas province, to understand the drivers of vulnerability and resilience to climate change according to local perspectives. The paper replicates many of the same methods used in Fazey et al. (2011) and explores how alternative forms of knowledge to Western science can be used to understand social dynamics. By attempting to integrate some more conventional secondary data on climatic and environmental change, it seeks to exemplify how Indigenous and Western forms of knowledge can complement and support each other in academic research. Specifically, the paper answers four interrelated questions: 1) What changes are occurring in Playitas? 2) What are the interactions between these changing conditions and how do they generate key drivers of change? 3) Are the changes in and responses of the community overall increasing or decreasing stress in the socioecological system? 4) How do the trajectories of change and response in the community affect vulnerability and resilience to climate change?

\section{Method}

\section{a. Study area}

Playitas is a neighborhood in the corregimiento of Guabal in the province of Veraguas in Panama. Settlement in Guabal is concentrated in the tropical deciduous forests along the Calovébora River in the piedmont areas of the central Panamanian Atlantic slope. The Calovébora River divides the semiautonomous NgöbeBugle comarca to the west, where the Panamanian state recognizes inhabitants' communal rights to the land, from the Veraguas province to the east, where inhabitants do not benefit from any legalized form of land tenure. The land highlighted in orange in Fig. 1 was the territory included in the original Ngöbe-Buglé land claim that remains without any form of legal recognition.

Permanent settlement in Playitas began in the 1970s, as families established households and plots concentrated around the Calovébora, which is marked in blue in Fig. 1, but the land had been in use by many of these same families for agricultural purposes for many years prior. Today, there are approximately 22 households, some of which are in multihome compounds that are home to more than one nuclear family, in the neighborhood, with a population of $\sim 250$ inhabitants, all of whom are Ngöbe and/or Buglé. Livelihoods are based on swidden agriculture consisting in including cultivating plots (e.g., plantain and banana varieties, yucca, and yams), gathering an array of useful plants (e.g., medicinal and edible herbs, flowers, and fruits), and hunting and fishing (e.g., for titi, 


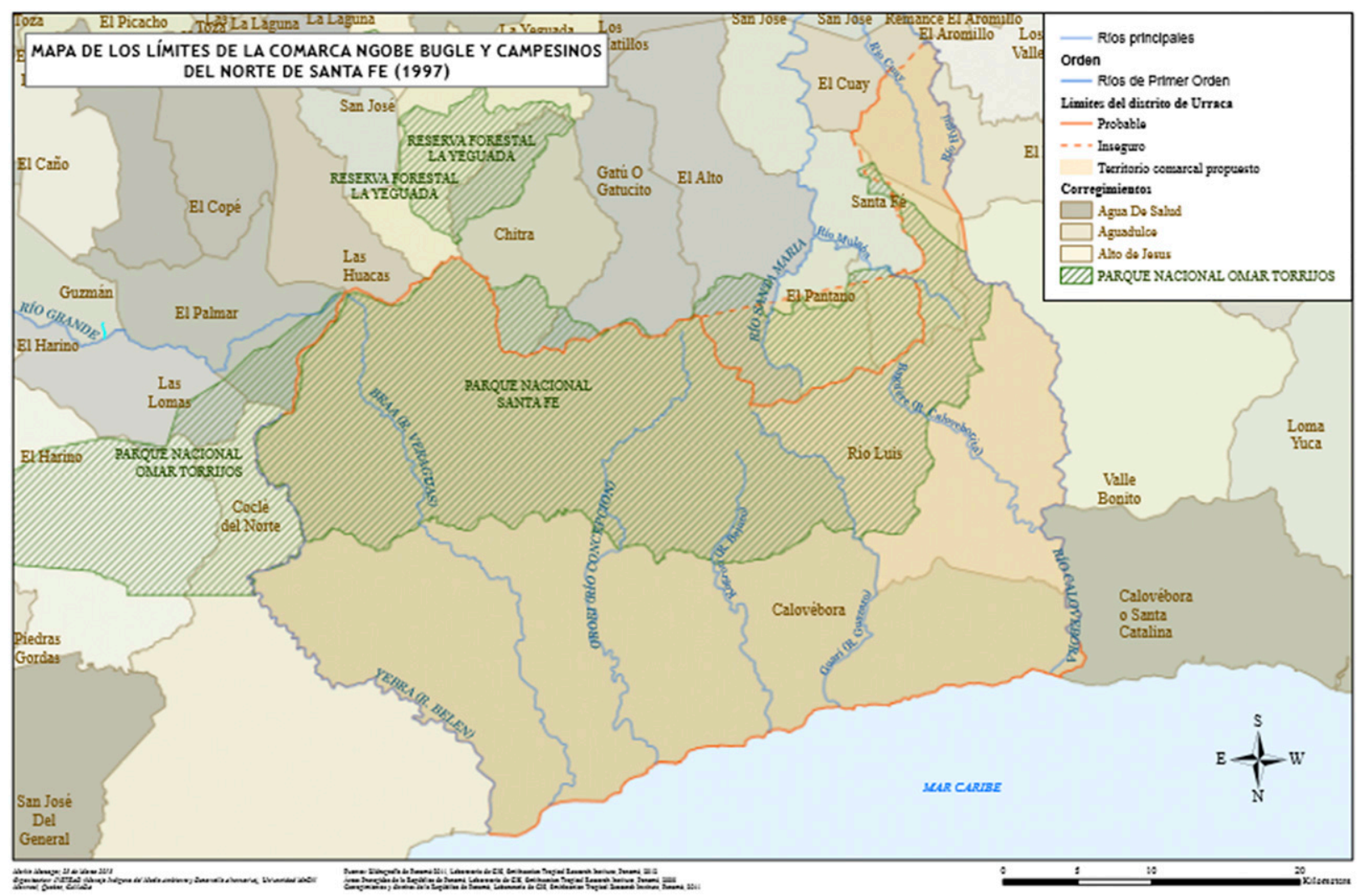

FIG. 1. Demarcations of the proposed land claim for the Ngöbe-Buglé occupied territory. The area included in the proposal is filled in with pink (Atlas de los Pueblos Originarios del Distrito de Urracá 2015, unpublished manuscript from La organización Quibian-Nune Köre-Toi Gnätaklne elegida por el Congreso Local del Distrito de Urracá).

medium-sized rodents, and, occasionally, wild boars). Plots exist in a mosaic of communal and private tenure, the complex dynamics of which are mediated by kinship ties, communal rules of behavior, and informal exchanges. Agricultural practices are governed by various customs/ behaviors considered traditional, including ajuntas, or collective farming outings, as well as rituals to bless the land and crops. Traditionally, families in the community participate in most aspects of each others' livelihoods, from raising children to clearing land to feeding mouths. It is common for community members to visit with other families at any time of the day and expect to at least be offered some chicha and a couple hours of conversation.

Inhabitants of the region have no formal rights to the land. Tenure insecurity is high and is exacerbated by growing land scarcity. The median monthly income per employed person was USD $\$ 49.50$, as compared with the provincial average of USD $\$ 220$, and $94.32 \%$ of inhabitants had no form of social security, as compared with the average rate of $59.04 \%$ in the rest of the province (Davis 2015). Commonly, the older generations of community members worked in construction or agriculture outside of the community for additional income, whereas younger community members were more likely to be attending school.

The region is remote and difficult to access, although the construction of a road connecting the nearest city, Santa Fe, to the Caribbean coast has been underway for decades. As of 2017, the vehicle-accessible road has extended to the community of Río Luis, which is now the last settlement in the central Atlantic region of the country that is reachable by standard vehicles. Playitas is located approximately $0.75 \mathrm{mi}(1 \mathrm{mi}=1.61 \mathrm{~km})$ downriver from Guabal's town center, but community settlements occupy the land bordering the river until it reaches the Caribbean Sea. Because Playitas and Guabal are closest to the road, their inhabitants interact most with travelers passing through. They are also the most exposed to developments and incursions into the area by foreigners, which are increasing as a result of the new infrastructure and growing interest in land for tourism, mining, and hydroelectric development.

The Organización Ambiental, which is an offshoot of the democratic Nuka Töre Indigenous governance body that exists within the comarca, is located in Playitas. It functions as a part of the greater governance structure, 
which includes various congresses and assemblies in which many different communities participate. The Organización Ambiental holds community meetings to inform inhabitants about current challenges, provide guidance for agriculture and other aspects of their livelihoods, and seek approval for projects, among other things. It is a critical source of information and organizational capacity for inhabitants. Meetings of the Organización Ambiental embody another component of the Ngöbe-Buglé communalism: open and participatory democracy. During meetings, every participant is invited to share their perspective and the leaders do not move on from a discussion point until all participants agree that there is nothing left to say. All community members above the age of 12 are allowed to vote on decisions made throughout the territory. The Organización Ambiental is the primary partner for the researchers and hosted the primary researcher during her stay in the community. Members of the Organización Ambiental also aided directly in conducting research.

The area in which Playitas is located has experienced and will continue to experience a variety of climate change effects. At present, mean annual temperature in Panama has increased by $0.35^{\circ} \mathrm{C}$ as compared with trends observed between 1980 and 1999 (https:// climatescreeningtools.worldbank.org/start-screening), with projections ranging from a $3^{\circ}$ to a $6^{\circ} \mathrm{C}$ increase for Panama by 2071-2100 as compared with 1990 according to the IPCC. This increases the risk of recurrent heatwaves (https:/climateknowledgeportal.worldbank.org/ sites/default/files/2018-10/wb_gfdrr_climate_change_ country_profile_for_PAN.pdf) and the intensity and frequency of tropical cyclones in the area (Campos et al. 1996).

Future precipitation variability is predicted for Central America (https:/climateknowledgeportal.worldbank.org/ sites/default/files/2018-10/wb_gfdrr_climate_change_ country_profile_for_PAN.pdf). Regionally, Bocas del Toro and Veraguas show the largest changes in precipitation of the four regions of Panama studied by Hidalgo et al. (2013). Further, Tremblay-Boyer and Anderson (2007) identified the Pacific and Caribbean sides of the western region of Panama as the most vulnerable to future climatic change using a "climatic space" variable, which measures average projected climatic changes in different ecosystem patches compared to interannual climatic variation in the past 40 years.

A drying pattern is predicted for Central America, with a decrease in summer precipitation and intensification of the mid-summer drought phenomenon (Fábrega et al. 2013; Hidalgo et al. 2013). Drought and heat stress increase the vulnerability of forests to tree mortality, and this effect has already been noted in Panama, where seasonal droughts following ENSO years have increased tree mortality (Allen et al. 2010; Condit et al. 1995; Leigh et al. 1990). The increased risk of droughts and higher temperatures in Panama suggest that forest mortality is a considerable risk, even in forests typically not thought to be water limited, including tropical broadleaf forests such as the one in which Playitas is located (Allen et al. 2010). Meteorological change, including changes in extreme weather events, rainfall, and evapotranspiration, has a variety of impacts on the availability and magnitude of water resources. Changes in water levels and freshwater life could have significant ramifications for livelihoods in Playitas, for which the Calovébora River is a critical resource.

\section{b. Conceptual approach}

This study employs a decision-oriented approach to understand how dynamics of change and response in Playitas influence both the resilience and vulnerability of the social-ecological system. As such, the complementary and overlapping contributions of resilience and vulnerability-based approaches are useful, as decisionmakers can employ them to evaluate how actions could strengthen resilience or reduce vulnerability (Câmpeanu and Fazey 2014; Maru et al. 2014; Schwarz et al. 2011). The parameters of change and response in Playitas are subject to significant uncertainties, multiscalar effects, various exposures, and subjective valuations of community members. Thus, an approach to adaptation that is capable of cycling between incremental responses that address proximate causes of vulnerability as well as systematic responses that build toward transformative change is needed (Fazey et al. 2011; Maru et al. 2014; Schwarz et al. 2011). Assessing the ways in which processes of change and response influence both resilience and vulnerability in the community allows for the examination of root and proximate causes to enable decisionmaking about how and when to prioritize transformational versus incremental responses to change and link long-term system drivers with local socioeconomic realities (Câmpeanu and Fazey 2014; Maru et al. 2014; Schwarz et al. 2011). Employing a pathways linked framework aids in visualizing how relevant adaptive capacity, resource access, and decision-making, which produce current or short-term vulnerability, are shaped by the broader processes that determine community resilience. This helps us understand vulnerability and adaptation as relevant beyond specific risks and events (Câmpeanu and Fazey 2014; Schwarz et al. 2011). With this understanding, this study proceeds with a "contextual" understanding of vulnerability, in which vulnerability is dynamically produced as function of sensitivity and exposure to climate change and adaptive capacity (Ford and Goldhar 2012; O'Brien et al. 2007; Smit and 
Wandel 2006), thus emphasizing the process-based and multidimensional view of the social-ecological system (Maru et al. 2014). It also employs Folke's (2006) normative definition of resilience as the ability of the system to absorb change while continuing to advance toward long-term development that is socially desirable. Nonetheless, both vulnerability and resilience are understood as dynamic and process-based, influencing each other through changes in adaptive capacity governed by both internal and external factors.

The trajectories-of-change method used by Fazey et al. (2011) is the guiding conceptual model for this analysis. They define a trajectory of change as "a dynamic process of individual, group and/or societal responses to change which create further change and responses with outcomes that reflect the cumulative properties of that process" (p. 1276). The concept of pathways of change helps to determine what adaptation is "about" (Wise et al. 2014), or, in other words, to understand the need for action either as a response to change or as a proactive measure. The pathways approach is conceptualized in the literature as an approach to evaluate and sequence a series of adaptation decisions considering their interactions with uncertain future scenarios over time to enable better informed decision-making (Haasnoot et al. 2013; Haasnoot et al. 2012). It recognizes adaptation as part of the pathways of change and response in a socialecological system and thus emphasizes the process of decision-making under conditions of uncertainty and extreme complexity (Pelling and Manuel-Navarrete 2011; Reeder and Ranger 2011; Wise et al. 2014). By taking into account both proximate and root causes of vulnerability and their interactions over time, the pathways approach can be used to accommodate both short-term responses and long-term resilience-building strategies while attempting to avoid maladaptations (Fazey et al. 2011; Wise et al. 2014). Instead of using "adaptation pathways" in the policy sense as in Haasnoot et al. (2012, 2013), this study focuses on the coping methods and adaptive strategies used by community members to deal with stress and change and the response of the socialecological system to these coping methods. This allows for an initial understanding of the nature of interactions between different components of their social-ecological system so that different scenarios of future change may be more accurately considered (Fazey et al. 2011; Maru et al. 2014). It relies primarily on field data conducted in Playitas and is supplemented by external information on climate change projections and demographic data for the area. This study demonstrates how the trajectories-of-change model can utilize primarily perception-based information to assess relationships between drivers of change in a community in the absence of other forms of data.
The trajectories of change are modeled as causal-loop diagrams, that is, conceptual models in which items of change are connected through directional polarized arrows, with the arrows demonstrating the direction of influence and their polarity indicating the nature of change. Causal-loop analysis then allows for the identification of key balancing and reinforcing feedback loops and overall directions of change where applicable (Downing et al. 2014). The key drivers of change in the system were identified by how many other variables they influenced directly or indirectly, thus indicating the strength of their influence on the pathways of change in the community (Fazey et al. 2011; Maru et al. 2014).

\section{c. Methods}

The field research was conducted between June and August of 2016. All of the methods were executed in compliance with McGill University's Research Ethics Requirements, and involved close collaboration between the research team, the Center for Indigenous Conservation and Development Alternatives (CICADA) and the Organización Ambiental de Playitas, and community members. The research took place as part of an ongoing relationship and series of projects between CICADA and the Organización Ambiental, which have involved land use mapping, Indigenous storytelling, and rights-based advocacy. For this project, mixed methods were used to gain a qualitative understanding of pathways of change, livelihoods, current stresses, and impacts of experienced climate and environmental change in the community, with local research assistants from the Organización Ambiental working closely with the primary researcher. Knowledge gained during other projects supplemented the information gained through interviews. Land use mapping, for example, gave the primary researcher a more complete picture of the community's livelihoods while accompanying community members on harvest trips gave her a holistic understanding of their subsistence practices. The primacy given to the perceptions expressed during interviews and conversations means that the use of terms such as "traditional practices" refers to the ways in which community members themselves used these terms. More specific references are included where community members spoke more specifically.

We conducted two sets of interviews with each participant family $(n=26)$, some of whom were living in shared households. In the first set, family members were asked questions that attempted to get a sense of how life used to be and how and why it has changed. The themes and questions discussed during the interviews were based on important themes that emerged during activities completed with the community in previous years and were confirmed during the initial community focus-group 
meetings. The interviews were semistructured and targeted specific areas identified by researchers by asking interviewees to compare how certain items were in the past with how they are today. For instance, interviewees were asked if they had observed any changes in the natural environment, what these changes are, how they are changing, and what they perceive to be the causes of these changes. The primary researcher quickly noticed that community members did not mark or observe time according to conventional calendar years and temporal periods were thus ascertained depending on when they occurred in relation to when families arrived in the area. Nonetheless, many interviewees categorized time in terms such as "then" or "during those times."

One member of the Organización Ambiental accompanied author $\mathrm{A}$. $\mathrm{Li}$, the primary researcher, on the interviews, which were all conducted in Spanish, and helped with some minor translations for older community members for whom Spanish was a second language. They assisted not only in direct translation but also in helping to explain research questions when interviewees were unclear about their meaning. Due to common living arrangements and customs, the vast majority of interviews were conducted with at least two family members present, and family members assisted each other in responding to questions. In various cases, researchers noticed that male family members would often respond in the place of a female interviewee, even when the questions were directed to the woman. Attempts were made to remedy this by following up in more private conversations with female respondents.

Once the primary researcher became able to communicate more clearly with interviewees, the research team decided that the member of the Organización Ambiental would remain outside during the interview so as not to influence interviewees' answers. The primary researcher took notes by hand during the interviews to capture responses. The primary themes of the semistructured interviews were environmental change, demographic change, and sociocultural change. All of the interviews took place in interviewees' respective homes.

The second, shorter, set of interviews was designed to develop understanding on cultivars, cultivation patterns, and the subsistence system of the communities. The primary researcher, at least one member of the Organización Ambiental, and at least one member of the interviewee's family visited between one and five different plots that families were cultivating. During these visits, interviewees answered questions about the crops used, cultivation methods, lengths of agricultural cycles, and changes in production on the plot in question. The number of plots the group was able to visit depended largely on their distance to Playitas. Some plots were located in other regions entirely, and resources did not allow for the researchers to visit those. As such, closer plots were certainly more represented in the research. Further, the researchers were able to visit several plots that were at least a 90-min distance by foot from Playitas. In some instances, the local research assistants visited the plots and recorded the associated information to save time.

Focus-group workshops were also held in which community members were informed about the project and were able to ask questions about it. Community meetings served as a space in which community members could discuss any concerns about the research and speak as a group about elements that they wanted to be represented in the final product. These meetings were announced in the same fashion as regular community meetings in Playitas: in the days prior, members of the Organización Ambiental visited peoples' homes and informed them that a community meeting was to take place, and on the day of the meeting they blew a conch to alert community members that the meeting was beginning shortly. Five such formal meetings were held during the course of the field research (attended by between 11 and 23 individuals). During the meetings, the researchers and members of the Organización Ambiental either made an announcement or explained some component of the research and invited suggestions, questions, and comments. Discussions moved freely, and everyone in attendance was given the chance to speak. During these meetings, community members expressed concerns about the trustworthiness of the foreign researcher, helped reframe some interview questions to be more appropriate, and gave feedback on initial results. Interviewees were selected from those who attended the meetings, given that they were those who were best informed about the project and freely volunteered to participate. Given the open and democratic nature of discourse in community meetings, it was not desirable to impose a robust methodological structure therein.

Longer, unstructured conversations between the primary researcher and members of the Organización Ambiental were invaluable for interpreting the findings in the interviews. These conversations were usually directed toward clarifying a particular point in an interview or in helping the primary researcher make connections between different elements. Given the relatively short duration of the field research, these discussions allowed the primary researcher to gain a deeper understanding of local dynamics and customs. The primary researcher also used these conversations to verify the connections they were making during the analysis phase. 


\section{d. Analysis}

\section{1) Changes occurring in Playitas}

Change was explored by asking interviewees to compare how things operated in the past to how they currently exist. Given the lack of specific temporal data, the researcher attempted to frame questions such that interviewees compared existing conditions with how they were when their family arrived in the area. As such, the change reflected in the analysis attempts to categorize changes that have occurred since the first wave of settlement in the area until the present. The primary researcher then coded the responses about change to generate two lists, one that compiled the specific items of change identified by interviewees and one that listed the broader types of change occurring in Playitas. From the items of change, each of which was associated with a broader type of change, the researchers were able to deduce the types of change that were most important according to the perceptions of community members. If many of the items of change were considered to be "cultural" types of change, for instance, the researchers could deduce that many elements in what is considered cultural are changing.

These lists include the direction of change (increasing or decreasing) and reasons cited by interviewees for the change. The weights of different drivers or elements of change were initially assigned according to the frequency with which the type of change was mentioned by interviewees and then was either adjusted or confirmed in conjunction with in-depth discussions with members of the Organización Ambiental.

\section{2) CAUSAL-LOOP DIAGRAMS}

Using the information about directionality and causality of changes discussed by interviewees, the researchers constructed diagrams that illustrated the linkages between different items of change. With the help of research assistants, causal-loop diagrams were then compiled from these diagrams, indicating the influences of different items of change on one another. Important current and future stresses and vulnerabilities in the community were identified through causal-loop analysis through the integration of field data and projections on the impacts of climate change in the area. Recommendations and policy prescriptions for the community are given on the basis of these analyses as well as conversations with community members about possible and desirable adaptive strategies.

In the next sections, we organize the results in this order, beginning with an overview of the items of change and the causal-loop diagrams followed by a discussion of how these changes relate to the community's vulnerability and resilience to climate change.

\section{Results}

\section{a. Items of change}

Participants identified a wide array of items of change. These items were categorized into six different types of change to facilitate understanding of general drivers of change in the community (see Table 1). There was a significant agreement over the first few items of change, with all items documented by more than one interviewee. Conversations with members of the Organización Ambiental revealed that many of these items of change, because they are prevalent concerns of community members, are often discussed in community meetings.

\section{b. Trajectories of change}

Several trajectories of change were identified from the items of change and interlinkages discussed in the interviews. First, there is a reinforcing feedback loop between agriculture and the monetary economy in which population, employment, and crop productivity are key drivers in increasing stress in food systems (Fig. 2). There is also an important socioenvironmental feedback loop in which demographic change is a key driver in promoting environmental changes that are largely perceived as negative (Fig. 3). Third, there are feedbacks between elements conceived as cultural and the prevalence of the monetary economy, in which the increasing prevalence of the market drives cultural loss (Fig. 4). These feedback loops are combined in Fig. 5 to visualize the interlinkages between all items of change in Playitas.

\section{1) Agricultural AND ECONOMIC FEEDBACKS}

Changes in the local economy and agriculture were often cited by interviewees in conjunction with one another, in which increasing economic activity (e.g., participation in wage labor or purchasing from the local supermarket) contributes to lowering agricultural productivity. Four interviewees discussed how less time is spent on traditional agricultural activities as more adults migrate outward from the area or spend more time working in jobs outside the community, thus reducing productivity as their agricultural systems require substantial manpower and time to maintain productivity. Increased monetary wealth allows them to substitute store-bought items for traditional agricultural food staples to supplement for losses in agricultural productivity. This feedback loop is shown in association with internal factors such as population growth and land scarcity as well as external factors such as government policy and development. As such, the relationship among declining agricultural productivity, land scarcity, and economic activity is a self-reinforcing one in 
TABLE 1. The 20 most frequently identified items of change in interviews (of 26). "Type of change" refers to the broader category of which the item is a part. "Direction of change" indicates whether the item is increasing or decreasing $(\downarrow=$ decreasing; $\uparrow=$ increasing).

\begin{tabular}{llcr}
\hline \hline \multicolumn{1}{c}{ Type of } & \multicolumn{1}{c}{ Item changing } & $\begin{array}{c}\text { Direction of } \\
\text { change }\end{array}$ & $N$ \\
\hline Environment & Forest cover & $\downarrow$ & 17 \\
Economy & $\begin{array}{l}\text { Proportion of purchased } \\
\text { items }\end{array}$ & $\uparrow$ & 15 \\
Social & Cultural loss & $\uparrow$ & 15 \\
Agriculture & Forest burning & $\downarrow$ & 13 \\
External & Land speculation/selling & $\uparrow$ & 13 \\
Land & Amount of land available & $\downarrow$ & 12 \\
Land & Sale and purchase of land & $\uparrow$ & 12 \\
Agriculture & Productivity of plots & $\downarrow$ & 11 \\
Agriculture & Juntas & $\downarrow$ & 10 \\
Environment & Temperature & $\uparrow$ & 10 \\
Environment & Climate variability & $\uparrow$ & 10 \\
Environment & River levels & $\downarrow$ & 9 \\
Economy & Employment & $\uparrow$ & 8 \\
External & Development & $\uparrow$ & 8 \\
Agriculture & Order in crops & $\uparrow$ & 8 \\
Medicine & Traditional medicine & $\downarrow$ & 7 \\
Environment & Plagues & $\uparrow$ & 7 \\
Land & Conflicts over land & $\uparrow$ & 6 \\
Environment & Fish populations & $\downarrow$ & 6 \\
\hline
\end{tabular}

which increasing development and population growth are key drivers in promoting stress in agricultural systems and reliance on income generation.

\section{2) SOCIAL-ENVIRONMENTAL FEEDBACKS}

Almost all interviewees identified several items of environmental change, including changes in agricultural productivity, with a feedback loop between social and environmental change illustrated in Fig. 2. The most cited sources of environmental change by interviewees were reduction in forest cover $(n=17)$, temperature increase $(n=10)$, increasing climate variability $(n=10)$, and lower river levels $(n=9)$. These items of change were most commonly associated with sociocultural, land use, and demographic change, although anthropogenic climate change was also cited as a driver of change by three interviewees. Population increase is a key driver in this system, cited as a reason for higher levels of pollution and land devoted to agriculture and for decreases in river levels, fish populations, wildlife populations, and forested areas on land. Interviewees explained this by saying that families were clearing tracts of forest more often and for longer periods of time to accommodate a growing population. Interviewees associated these behaviors with observed increases in plagues and decreases in crop productivity and wildlife. While interviewees attributed certain changes such as increases in pollution and the lowering of the river levels to their own behavior, external drivers including climate change and increasing development were also cited as drivers for some larger changes, such as temperature increases, climate variability, and pests.

\section{3) Sociocultural FeEDBACKS}

There are links between increasing development and reductions in activities considered to be culturally traditional, shown in Fig. 3. There are only two complete sociocultural feedback loops in the community and it appears that external factors are most important in driving observed changes. Increasing development of basic services and commercial industry (e.g., transportation, schools, medical services) in the area has increased the proportion of individuals receiving an education and employment, which decreases the time available for traditional cultural and agricultural activities. Reduced time for agricultural activities reduces forest burning $(n=13)$ and the frequency of ajuntas, or collective farming outings $(n=10)$. Because these traditional activities are centered around agriculture, this reduction has also been linked to decreasing agricultural productivity, which contributes to external migration for employment and the initial condition of less time devoted to traditional activities.

The communality of livelihood arrangements has long been regarded as a central component of the cultural life of the region and there are several factors that are contributing to its perceived decline. Overall, interviewees noted that notions of private property are increasing $(n=4)$, which contributes to the overall perceived decrease in the sense of communal life and reciprocity. Development has also led to declines in the proportion of traditional medicine used $(n=7)$ and increases in the proportion of purchased foods $(n=15)$. Immigration and education were the only factors mentioned as driving the increased discomfort with their Indigenous identity and their involvement in activities considered traditionally Indigenous. Conversations held with community members suggest that this results from increased exposure to nonIndigenous individuals, which is a result of development, which brings outsiders to the region, and outmigration. One elder in the community discussed how the roles of the cacique, the traditional chief, and the sukias, or traditional healers, have progressively declined in importance as a result of the generational passing of individuals who transmitted this knowledge, the lack of will to pursue the revival of certain traditional practices, and inertia in the community. Encroachment on land, represented in Fig. 3 as land speculation, development, and the construction of the road, puts additional pressure on land availability and increases perceptions of tenure 


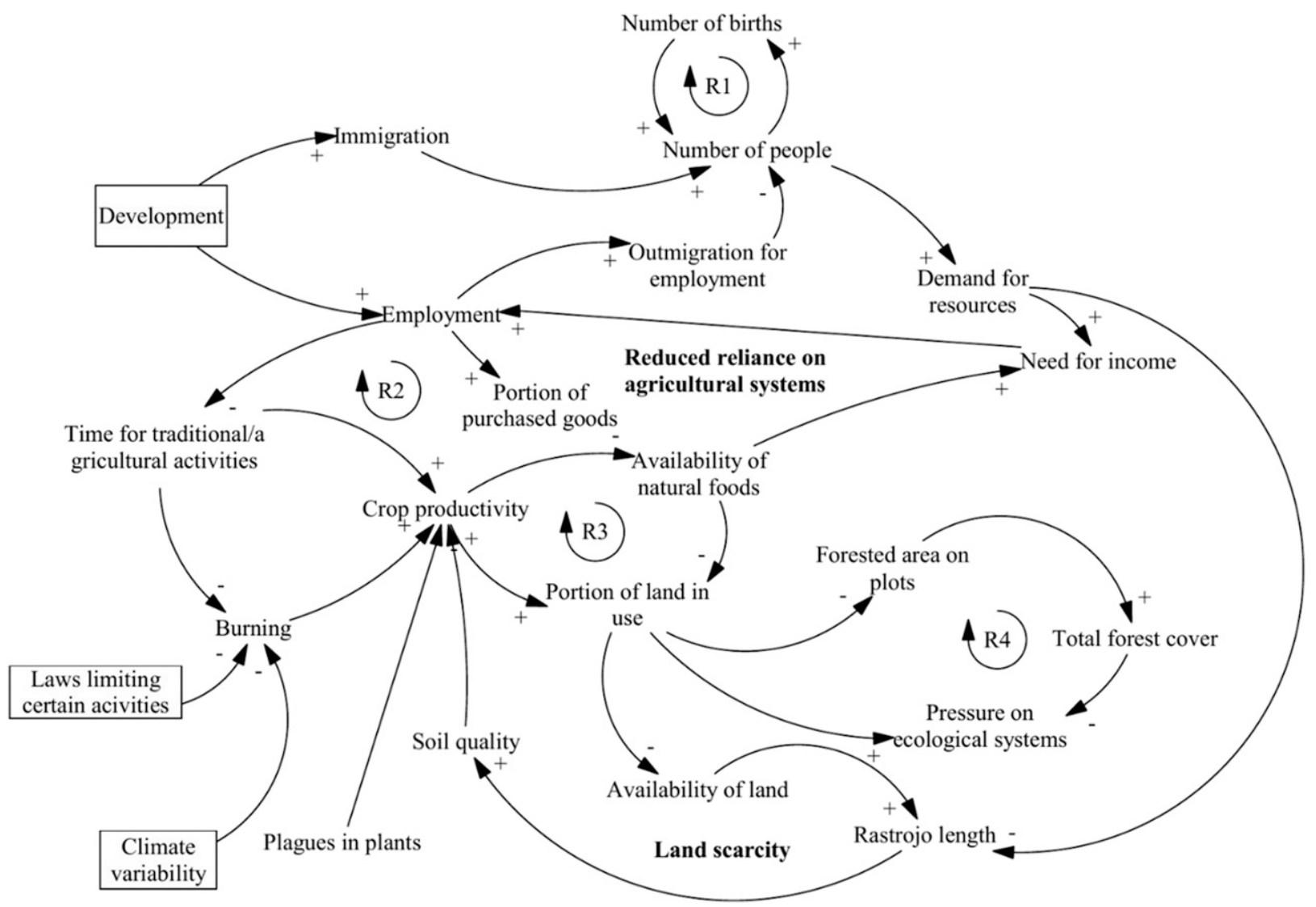

FIG. 2. Feedbacks of increased employment, declining agricultural productivity, and time-use tradeoffs in Playitas. The "R" indicates a reinforcing feedback loop. Arrows indicate the influence of one variable on another, and the polarity of the arrow indicates the nature of this influence (a positive polarity indicates that when the initial variable increases or decreases, the second variable changes in the same direction; a minus polarity indicates that when the initial variable increases or decreases, the second variable changes in the opposite direction).

insecurity, which interviewees associated with increasing notions of private property.

\section{4) KeY DRIVERS AND TRAJECTORIES OF CHANGE}

The key drivers of change in Playitas are both internal and external. The interactions between items of change in the whole system are illustrated in Fig. 5. Population growth and development are the two drivers identified most frequently in conjunction with changes occurring in the community, with climatic change acting as an important contributing factor. Population size and development were each associated with essential points of leverage in the system, such as land availability, time available for subsistence activities, and crop productivity, which are all closely tied to livelihoods and therefore generate changes much more noticeable for community members. These two key drivers exerted pressure causing other items in the system to change noticeably, which in turn affected other items in the system, resulting in cascading changes in some cases. Population growth is linked with land scarcity and environmental change, which contribute directly and indirectly to decreased crop productivity, increased reliance on purchased goods, cultural loss, and increased outmigration for employment. Increasing development contributes to increased employment and income generation, which is linked to bringing in external goods such as Western medicine, which also contributes to decreased crop productivity, increased reliance on goods, and cultural loss. Community members also perceive that development has increased population levels, as a result of increased immigration and longer life expectancy resulting from the increased availability of Western medical attention and stable sources of nutrition. Climatic and environmental changes occurring in the area are additional pressures that appear to exacerbate the negative impacts of changes caused by the two key drivers. Although determining the extent of current climatic change in Playitas is beyond the scope of this paper, the changes noted by community members-notably more frequent dry periods, increased 


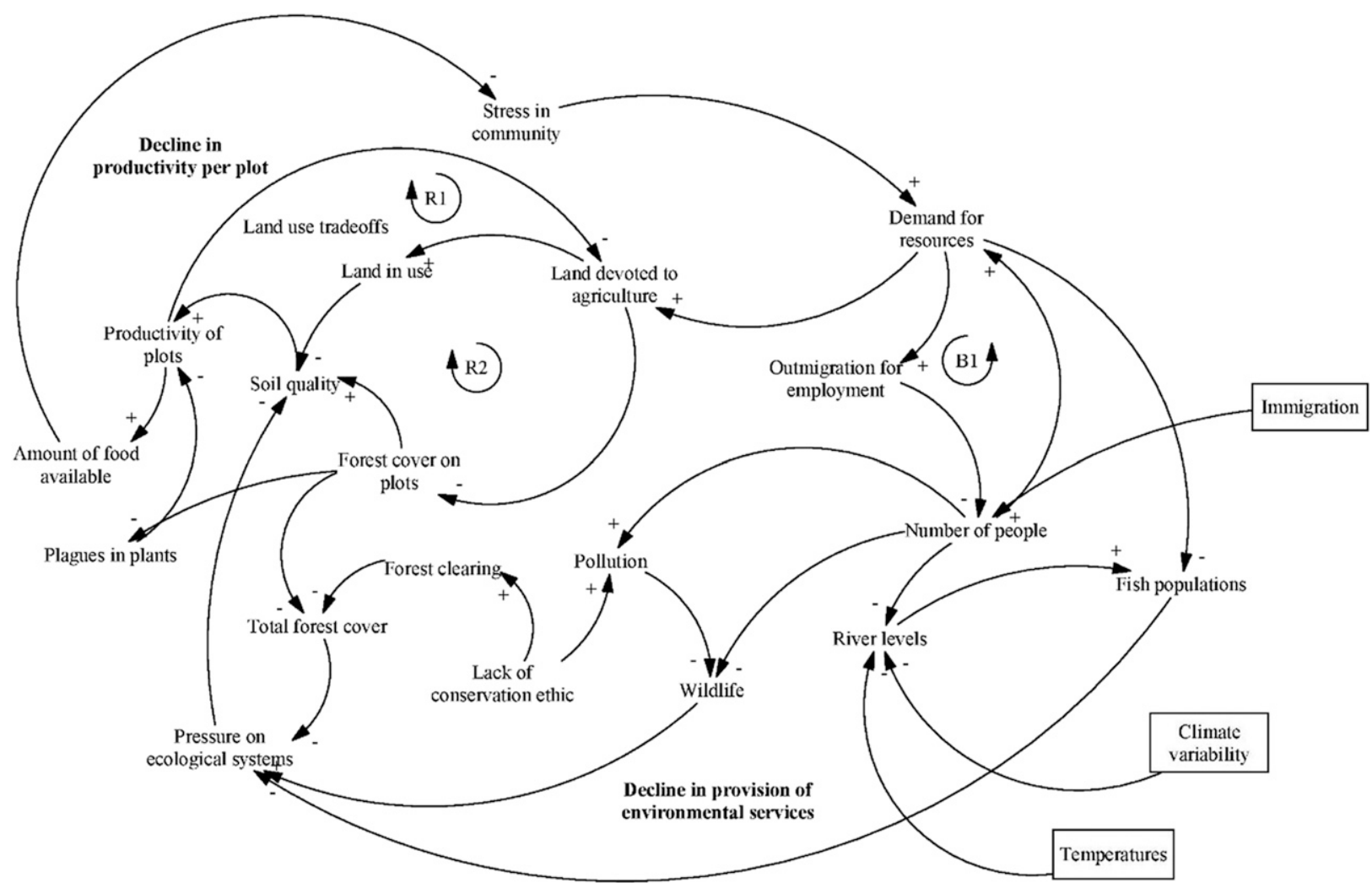

FIG. 3. As in Fig. 2, but for feedbacks of environmental change, decreasing agricultural productivity, and stress in the community of Playitas. The "B" indicates a balancing feedback loop.

climatic variability, increased temperatures, lower water levels in the river, and less biodiversity-corroborate the findings of other research on climate change in the region (Magrin et al. 2014; Nyong et al. 2007).

Both of these drivers appear to be contributing to largely reinforcing feedback loops and community perceptions do not indicate that any significant factors are balancing them at present. Outmigration for employment does limit the impacts of larger population sizes, but is often only temporary. Further, these drivers are themselves highly interlinked, with development appearing to increase the rate of population growth. Community members expressed particular uncertainty regarding the future of development. Because the Panamanian State does not currently recognize their native rights to the land, they are not ensured a collective say in the rate or type of development that takes place on their land or the land surrounding it. The development of the first vehicle-accessible road in the area, a state-funded project named "La conquista del Atlántico," has a stated objective of driving tourism and facilitating resource extraction and energy transmission in the area. The community can likely not have a noticeable effect on climate change, but local environmental conditions, particularly forest density and health, may impact the extent to which climate changes impact livelihoods and are felt by the community. Community responses did not indicate that there were many substantive factors limiting population growth and development, which appeared to have the largest influence in environmental quality. The Organización Ambiental claims to do its best to advise people to engage in beneficial environmental practices, but their success has been limited.

Conversely, some items that were discussed frequently by community members, such as land speculation/selling $(n=13)$, sale and purchase of land $(n=12)$, and conflict over land $(n=6)$, did not actually appear to play a large role in affecting other forms of change in the system other than the conceptions of private property and perceptions of community cohesion. This reflects the sentiment of tenure insecurity that pervades the community. While this fear has yet to materialize for most of the community and therefore has not begun to have concrete impacts in terms of change, it provides a clearer picture of the current atmosphere in the community and the types of change that are undesirable for community members. Including these variables in the causal-loop diagram gives credit to the importance of such perceptions in a context 


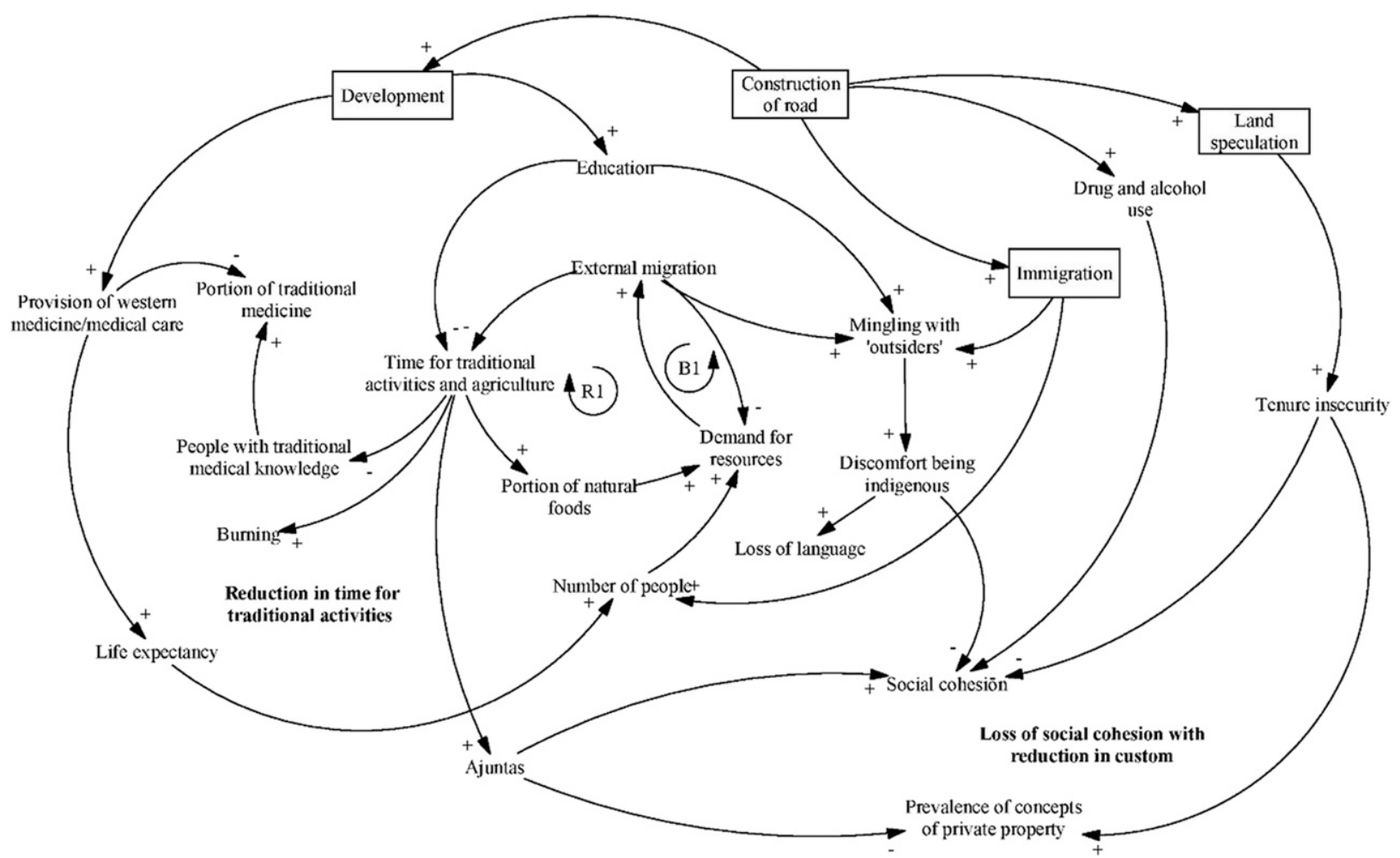

FIG. 4. As in Fig. 2, but showing additional feedbacks of increasing development, increasing market access, and declines in some cultural activities in Playitas.

in which the sense of insecurity alone can affect the health of the socioecological system. In this case, the perception that community members are more willing to sell their land, even if unfounded, can impact how willing individuals are to share their resources with others or act in ways that are collectively beneficial. As such, although these smaller variables, which also include outmigration for employment, drug and alcohol use, and provision of Western medical care, exert less individual pressure on other items in the system, they are essential to include because they provide a deeper understanding of how community members conceive of these issues and how to address them.

\section{Discussion}

The Playitas social-ecological system is experiencing rapid rates of change that are increasing stress in several areas of community livelihoods. The understanding of current dynamics of change and vulnerability provides the basis to allow for the assessment of possible future vulnerabilities in the community. Similar to McCubbin et al. (2015), it appears that, while Playitas is sensitive to current and future climatic stressors, nonclimatic stressors appear to have the most influence on social-ecological wellbeing. Climatic factors were most commonly described in the context of their relationship to a complex set of social, cultural, historical, and ecological factors.

As highlighted in other community-based studies (Butler et al. 2014; Câmpeanu and Fazey 2014), it is important to consider vulnerability and resilience to climate change as part of the broader network of decision-making and livelihoods in which communities are engaged. Vulnerability and resilience are both dynamic and heterogeneous throughout the different components of community livelihoods. Therefore, whereas the vulnerability or resilience of different aspects of the system has changed, this does not necessarily entail greater vulnerability or resilience of the system as a whole. The vulnerabilities highlighted in this paper predominantly concern the observable impacts of climate change on systems that are central to community livelihoods, as the research has prioritized the perspectives of community members (BeLue et al. 2012; Fazey et al. 2011; Ford et al. 2006; Mendoza and Prabhu 2005; Purnomo et al. 2004; van Aalst et al. 2008). The causal-loop analysis examined how internal dynamics affected the stability of the social-ecological system, and the following segment assesses how these trajectories of change implicate the community's vulnerability and resilience to climatic change. 


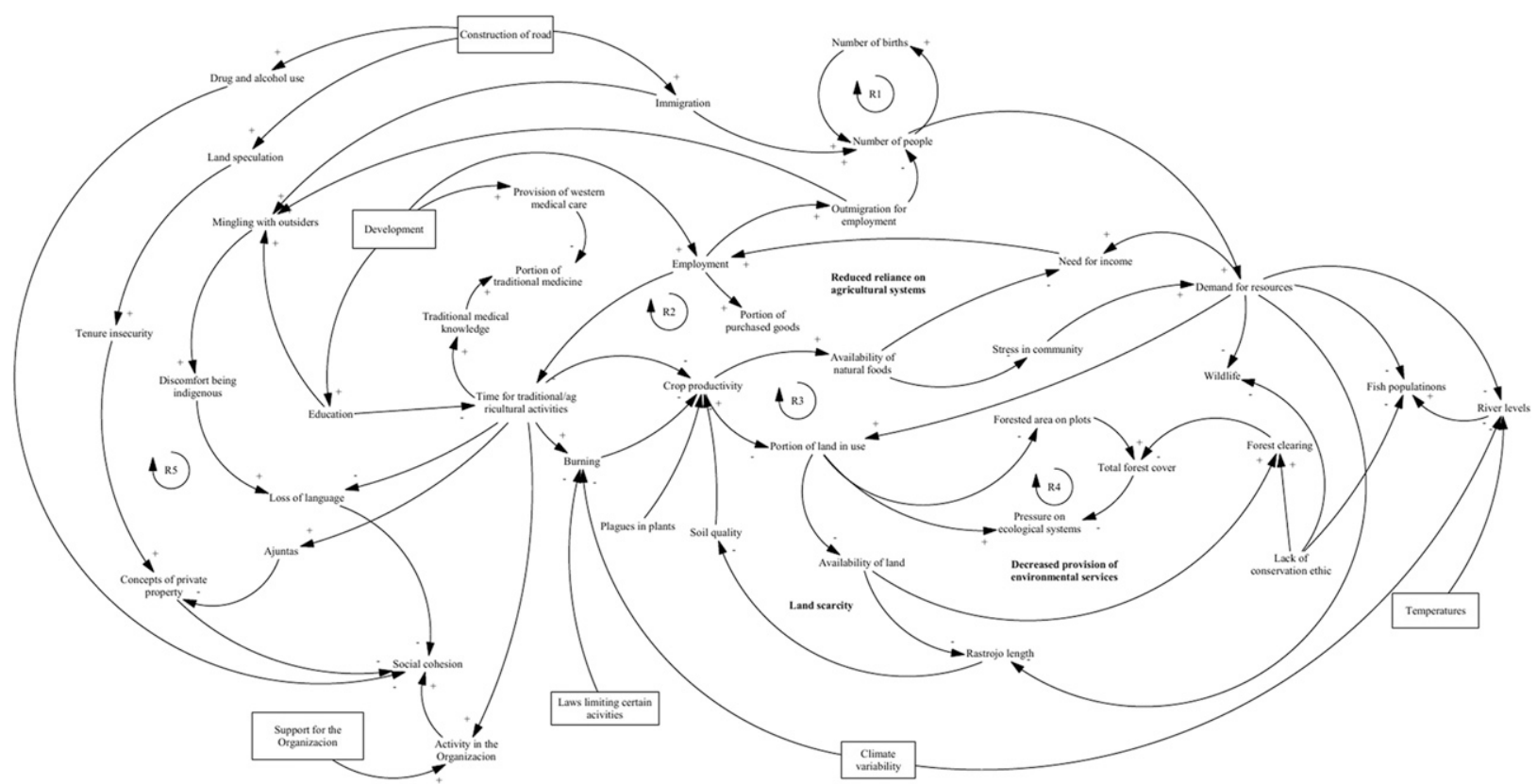

FIG. 5. As in Fig. 2, but showing a final causal-loop diagram of the Playitas social-ecological system with all feedbacks incorporated.

\section{a. Vulnerability}

In the past, community members' experience of stressors was determined by the extent of localized knowledge, social cohesion, and livelihood flexibility, but, at present, population growth, livelihood change, and increased local development have led to decreases in each of these items. Over time, the community has employed other strategies to cope with stress. While the changes that have occurred in recent generations have in many cases improved families' ability to manage shortterm stresses, they appear to be magnifying their sensitivity and exposure to longer-term shifts caused by such factors as climate change and market integration.

In the past, when the community was extremely difficult to access, community members' biggest sensitivity was to severe diseases or injuries that they were unable to treat themselves, although the exposure to such diseases was minimal. They were also sensitive to food shortages when crops failed, as there were few available alternative sources of food. In these situations, families would help each other when they could as widespread crop failures were rarer than they are today. With increasing market and societal integration, however, these parameters have shifted. While their mobile livelihoods allowed them to respond more freely to changing circumstances and incursions into their territory (Wickstrom 2003), Ngöbe and Buglé farmers today are more sedentary due to the decreased availability of public lands, increasing population, and reliance on centrally located basic services.
The agricultural system in Playitas appears to be under considerable stress and is demonstrating signs of increased vulnerability due to climate shifts. Agricultural productivity appears to respond negatively to the environmental changes occurring in the area, whether attributable to ecological changes such as reduced forest cover or to climatic shifts occurring over longer time scales, such as increased precipitation variability. Because there appears to be few controls on climatic changes or ecological degradations, it can be expected that the agricultural system's sensitivity and exposure to such changes will continue to increase.

The decline in provision of environmental services is a sign of a reduction in the health of the ecological system and results from existing climate change and human interference, suggesting that it will be less able to recover from exogenous shocks (De Lange et al. 2010). The response mechanisms employed by the community to cope with the proximate causes of environmental stress are increasing socioecological vulnerability to climate change. Clearing entire lots for cultivation rather than cultivating semiforested areas, a practice that community members employ with the aim of cultivating more crops, leaves the crops unprotected from extreme weather events. Community members also use other strategies to intensify their harvests when previous yields are lower than expected, such as harvesting more plots at once, which may increase yields in the short run but damage the agro-ecosystem in the long run. The reduced integrity of the agro-ecological system 
increases its sensitivity to shocks. As a result, there may be shifts in the ecosystem that are unpredictable, notably rapid degradation of ecosystem services on which the community relies. Some older community members expressed that although in the past they could predict such shifts they are unable to "read" the shocks that are occurring at present. Only some of the environmental changes discussed by interviewees can be attributed to climate change, namely temperature increases and climate variability. In particular, the most commonly listed shocks were large storms, which they described as more severe and frequent than they used to be but lasting less time. Indeed, variability appears to be the most important climatic variable affecting other items in the system. Because of this growing variability, community members are less able to plan widescale burns to clear the system, such that their swidden practice resembles more of a slash and mulch system rather than a slash and burn one. While this slows down the agricultural process, it may reduce local temperatures and burning-related emissions in the long run.

Although increased stress on agricultural systems threatens the internal stability of the socioenvironmental system, the increased diversity of income sources generally lessens families' sensitivity to agricultural shocks such as extreme weather or floods. As the community continues to be reliant on their agricultural system for more than half of their nutrition, however, they continue to be sensitive to crop failure, while climate change, ecological degradation, and erosion of traditional practices have increased their exposure to such shocks. There were conflicting views about whether having alternative sources of nutrition was beneficial. Some participants noted that the store-bought food ensured that their family always had more than one meal a day and that the store-bought foods made new and more varied types of food available. Equally, elder community members lamented that new food sources lack in nutrients when compared to natural cultivated crops such that new generations are growing up weaker than their parents. Dependence on storebought goods also exposes community members to the fluctuations of the market, similar to what is noted in Fazey et al. (2011).

Increased involvement in the market economy impacts the community's vulnerability to continued development or climate shocks. Internal sociocultural arrangements themselves appear to be vulnerable to change, as increased exposure to outsiders and latino culture lead to the reductions of traditional practices and, to some degree, communal relationships. These sociocultural changes, in turn, will likely impact the community's ability to respond collectively to climate shocks in the future, thus increasing their sensitivity.
This is because their swidden agricultural system requires large inputs of manual labor during concentrated time periods. As such, collective farming outings in which several families work together on one family's plot allowed families to work more efficiently and cultivate more plots at a given time. This mutual exchange of labor intensified senses of communality about food and other resources that helped any individual family survive shocks. As ajuntas and other traditional agricultural activities became more difficult to organize due to increasing time commitments, families adjusted by cultivating one plot more intensively and rotating cultivation plots less frequently, which caused more permanent forest cover loss and increased their sensitivity to crop failure.

If these trends continue, it will be difficult for the community to preserve components of Indigenous knowledge that have been accumulated over centuries. Although the challenges they face will be amplified and changed with the impacts of climate change, Indigenous knowledge remains critical to their adaptive capacity as it draws on lessons learned from prior experiences of climatic variability and natural resource disturbance in the area. In this sense, we consider Indigenous knowledge not as static information that would necessarily be outdated as time passes, but rather as a collective process of creating knowledge through observation and practices of relating to the land. What is decreasing in Playitas is not simply the accumulated information they have gathered through generations, but rather the practices associated with forming and sharing that knowledge in the community. Indigenous knowledge is tightly linked to the social cohesion of the community, as traditional practices bring community members together and traditional belief systems bolster communality, such that they have a positive reinforcing relationship. Social cohesion, exemplified in Playitas by such practices as land sharing and food gifting, contributes to the adaptive capacity of communities by allowing them to distribute the burden of climate or socioeconomic stressors (Ford et al. 2006; McCubbin et al. 2015). Thus, if this pathway leads to the loss of Indigenous knowledge, the community's coping mechanisms will magnify vulnerability to aforementioned stressors over time.

\section{b. Resilience}

In this context we consider resilience to signify the parameters of persistence, adaptability, and transformability that are desirable for the community (Folke 2006). The normative description of desirable outcomes allows us to move beyond the resilience of the system as it exists today and consider the possibilities for "no regrets" options that move toward goals that are overall perceived as beneficial 
and feasible in the community (Câmpeanu and Fazey 2014; Haasnoot et al. 2012; Wise et al. 2014).

Throughout history, the resilience of Ngöbe and Buglé communities resided in their extreme isolation, which necessitated total self-reliance (Wickstrom 2003). As forest dwellers, they learned how to feed themselves, treat illnesses, and respond to shocks using the tools provided and knowledge developed in their ecosystem. While death rates were higher and life expectancies shorter, their nomadic, shifting livelihoods and smaller population sizes allowed them to evade efforts to assimilate them into mainstream latino culture while maintaining their agricultural and sociocultural arrangements (Wickstrom 2003).

Their swidden agriculture system, the health of which is tied in with social customs, allows community members to avoid depleting soil quality while providing a buffer against shocks, since most families cultivate more than one plot at a time (García-Oliva et al. 1999; Kleinman et al. 1996; Kleinman et al. 1995; Padoch and Pinedo-Vasquez 2010; Palm et al. 1999; Pedroso-Junior et al. 2009; Tschakert et al. 2007; Van Vliet et al. 2013). The resilience of the system itself, however, is being challenged. On one hand, families have responded to increased climatic variability by burning less forest and to decreased agricultural productivity by decreasing fallow times and clearing more forest. While these changes indicate the adaptability of the system, only some changes, such as the decreased burning, are viewed as desirable by community members. The increased forest clearing and cultivation times, propelled by decreasing land availability and higher populations, are signs that some of the desirable aspects of the swidden system will not persist if they continue on this trajectory (Vosti and Witcover 1996). Other symptoms of agricultural stress and environmental change that were linked to these agricultural changes such as decreases in wildlife were also considered undesirable for community members. Nonetheless, the system continues to support a diversified cropping system in which community members conduct selective conservation and maintain culturally valuable practices that do not destroy their natural surroundings (Kleinman et al. 1995; Padoch and Pinedo-Vasquez 2010). While the swidden agricultural system is critical to community members' vision of the future, many community members recognize that increased access to markets may allow them to more easily adjust to longer-term reductions in agricultural productivity. Indigenous knowledge, which informs the community's current agricultural practices and communal arrangements, continues to represent a large source of community resilience despite increased involvement in the monetary economy. Despite the aforementioned decline of traditional practices in the community, Indigenous knowledge and practices still represent a significant source of resilience in the community. Knowledge about the plants and ecosystems allows community members to monitor changes in their surroundings, respond to climatic variability, and treat a variety of illnesses, among many other things. While notions of private property appear to be increasing, traditional forms of sharing knowledge, resources, and food persist and adapt to new tenure arrangements in the community. Consistent with other Indigenous populations, the pace and nature of some current changes caused by climate change and development may be unfamiliar and beyond the scope of knowledge developed about past events (Alexander et al. 2011; Ford et al. 2016; Maldonado et al. 2016). Nonetheless, the practice of forming and interpreting traditional ecological knowledge will remain an important and relevant source of information about ecological conditions and for planning adaptation responses (Berkes 1999; Berkes et al. 2000; Ford 2000; Pearce et al. 2018).

The strength of the Organización Ambiental will also continue to be important sources of adaptive capacity for the community as they seek to adjust to change. The Organización Ambiental provides a forum through which to discuss, implement and enforce adaptive strategies collectively, thus allowing for the identification of beneficial and feasible objectives. In the past, the Organización Ambiental and traditional authorities have played an important role in encouraging customary practices that contribute to the iteration of traditional ecological knowledge, bolster community support networks, and facilitate information sharing. These practices of sharing and communality provide resilience to shocks to their subsistence base and improve their ability to make decisions collectively, which all improve the likelihood of positive and beneficial outcomes in the long run. Therefore, it appears that continued participation in the Organización Ambiental and efforts to strengthen it, which are under way, will help the community adapt to changes over time. Community members expressed strong desires to implement projects that address language loss, incentivize local craft-making, and improve strategies for agricultural productivity and environmental conservation. However, the power of the Organización Ambiental is limited because of the lack of recognition of their land rights and authority. It is evident that increased governance over their land and resources would help ensure their resilience to future shocks over time, but this is largely dependent on their ability to achieve recognition from the state. 


\section{Conclusions}

In sum, while individuals' responses to changes driven by population growth, development, and environmental change are rational and even sometimes necessary shortterm responses to change, they are overwhelmingly exacerbating stress on an unsustainable trajectory. This is consistent with other studies of resource-dependent communities in which changing responses and circumstances are contributing to pathways of change that are at odds with long-term well-being, such as Fazey et al. (2011), Pearce et al. (2018), Butler et al. (2014), and Maru et al. (2014). This evidence also seems to corroborate the observation that climate change acts as a multiplier of existing vulnerabilities in marginalized populations (Ford et al. 2016; Green and Raygorodetsky 2010; Maru et al. 2014; Mearns and Norton 2010).

While development has led to some positive outcomes in terms of health and education, increased land scarcity and reliance on income, as well as decreased resource availability and agricultural productivity, will continue to be reinforced, increasing vulnerability to environmental disruptions and market fluctuations. As such, if the community of Playitas continues on the same trajectory, vulnerability to shocks in their agricultural and ecological systems will continue to grow. While some of these changes reduce vulnerability to shocks in the short term, this resilience often comes in a form that community members do not consider desirable. In the long run, key elements of livelihoods and agricultural systems will undergo significant if not transformative changes in response to climatic and economic changes in coming generations unless extreme action is taken to strengthen the resilience of the present system. Strengthening governance is key to improving resilience in a desirable manner. There is little that can be done at the community level to mitigate the effects of global climatic change, but the potential for increased drying patterns (Fábrega et al. 2013; Hidalgo et al. 2013), large-scale forest death due to drought and increased temperature (Allen et al. 2010), and increases in extreme weather events and their impacts (Campos et al. 1996; Rauscher et al. 2008) signals a need for adaptation interventions to reduce the magnitude of negative impacts experienced by the community.

The aim of this paper is practical in addition to academic; it seeks to produce knowledge that is appropriate and usable for the community with limited resources while exploring the possibilities for academic research in contexts with such limited information. The concept of trajectories of change allowed the researchers to identify key drivers of change and infer the amount of leverage each driver has on the system. By considering both vulnerability and resilience to exogenous changes, this study was able to analyze how changes influenced the impacts of changes felt by the community as well as elements that support their ability to achieve their long-term objectives.

Acknowledgments. The research presented in this paper was made possible by the generosity and hospitality of the community members of Playitas and Guabal, and specifically the tremendous assistance of specific persons in the community who assisted with logistical and programmatic elements of the field work and provided consistent guidance and support throughout. The first author gratefully acknowledges the Arts Internship Office of McGill University, who provided the funds that made the field component of this research possible.

\section{REFERENCES}

Adger, W. N., 2006: Vulnerability. Global Environ. Change, 16, 268-281, https://doi.org/10.1016/j.gloenvcha.2006.02.006.

Alexander, C., and Coauthors, 2011: Linking Indigenous and scientific knowledge of climate change. BioScience, 61, 477-484, https://doi.org/10.1525/bio.2011.61.6.10.

Allen, C. D., and Coauthors, 2010: A global overview of drought and heat-induced tree mortality reveals emerging climate change risks for forests. For. Ecol. Manage., 259, 660-684, https://doi.org/10.1016/j.foreco.2009.09.001.

Atlas de los Pueblos Originarios del Distrito de Urracá, 2015: La organización Quibian-Nune Köre-Toi Gnätaklne elegida por el Congreso Local del Distrito de Urracá.

Belfer, E., J. Ford, M. Maillet, M. Araos, and M. Flynn, 2019: Pursuing an Indigenous platform: Exploring opportunities and constraints for Indigenous participation in the UNFCCC. Global Environ. Polit., 19, 12-33, https://doi.org/10.1162/ glep_a_00489.

BeLue, R., C. Carmack, K. R. Myers, L. Weinreb-Welch, and E. J. Lengerich, 2012: Systems thinking tools as applied to community-based participatory research. Health Educ. Behav., 39, 745-751, https://doi.org/10.1177/1090198111430708.

Berkes, F., 1999: Sacred Ecology: Traditional Ecological Knowledge and Resource Management. Taylor and Francis, 209 pp.

, J. Colding, and C. Folke, 2000: Rediscovery of traditional ecological knowledge as adaptive management. Ecol. Appl., 10, 1251-1262, https://doi.org/10.1890/1051-0761(2000)010 [1251:ROTEKA]2.0.CO;2.

Butler, J. R. A., and Coauthors, 2014: Framing the application of adaptation pathways for rural livelihoods and global change in eastern Indonesian islands. Global Environ. Change, 28, 368382, https://doi.org/10.1016/j.gloenvcha.2013.12.004.

Câmpeanu, C. N., and I. Fazey, 2014: Adaptation and pathways of change and response: A case study from Eastern Europe. Global Environ. Change, 28, 351-367, https://doi.org/10.1016/ j.gloenvcha.2014.04.010.

Campos, M., A. Sánchez, and D. Espinoza, 1996: Adaptation of hydropower generation in Costa Rica and Panama to climate change. Adapting to Climate Change: An International Perspective, J. B. Smith et al., Eds., Springer, 232-242.

Castree, N., and Coauthors, 2014: Changing the intellectual climate. Nat. Climate Change, 4, 763-768, https://doi.org/10.1038/ nclimate2339. 
Condit, R., S. P. Hubbell, and R. B. Foster, 1995: Mortality rates of 205 neotropical tree and shrub species and the impact of a severe drought. Ecol. Monogr., 65, 419-439, https://doi.org/ $10.2307 / 2963497$.

Cutter, S. L., L. Barnes, M. Berry, C. Burton, E. Evans, E. Tate, and J. Webb, 2008: A place-based model for understanding community resilience to natural disasters. Global Environ. Change, 18, 598-606, https://doi.org/10.1016/j.gloenvcha.2008.07.013.

Davis, E., 2015: Diagnóstico de la Población Indígena de Panamá con base en los Censos de Población y Vivienda de 2010. Instituto Nacional de Estadística y Censo Rep., 186 pp., http:// www.contraloria.gob.pa/inec/archivos/P6571INDIGENA_ FINAL_FINAL.pdf.

De Lange, H. J., S. Sala, M. Vighi, and J. H. Faber, 2010: Ecological vulnerability in risk assessment-A review and perspectives. Sci. Total Environ., 408, 3871-3879, https://doi.org/10.1016/ j.scitotenv.2009.11.009.

Díaz, S., and Coauthors, 2015a: The IPBES Conceptual FrameworkConnecting nature and people. Curr. Opin. Environ. Sustain., 14, 1-16, https://doi.org/10.1016/j.cosust.2014.11.002.

— S. Demissew, C. Joly, W. M. Lonsdale, and A. Larigauderie, 2015b: A Rosetta stone for nature's benefits to people. PLoS Biol., 13, e1002040, https://doi.org/10.1371/journal.pbio.1002040.

Downing, A. S., and Coauthors, 2014: Coupled human and natural system dynamics as key to the sustainability of Lake Victoria's ecosystem services. Ecol. Soc., 19, 31, https://doi.org/10.5751/ ES-06965-190431.

Fábrega, J., and Coauthors, 2013: Hydroclimate projections for Panama in the late 21st century. Hydrol. Res. Lett., 7, 23-29, https://doi.org/10.3178/hrl.7.23.

Fazey, I., N. Pettorelli, J. Kenter, D. Wagatora, and D. Schuett, 2011: Maladaptive trajectories of change in Makira, Solomon Islands. Global Environ. Change, 21, 1275-1289, https:// doi.org/10.1016/j.gloenvcha.2011.07.006.

Folke, C., 2006: Resilience: The emergence of a perspective for social-ecological systems analyses. Global Environ. Change, 16, 253-267, https://doi.org/10.1016/j.gloenvcha.2006.04.002.

Ford, J., 2000: Traditional ecological knowledge, ecosystem science, and environmental management. Ecol. Appl., 10, 12491250, https://doi.org/10.1890/1051-0761(2000)010[1249:TEKESA] 2.0.CO;2.

Ford, J. D., and C. Goldhar, 2012: Climate change vulnerability and adaptation in resource dependent communities: A case study from West Greenland. Climate Res., 54, 181-196, https:// doi.org/10.3354/cr01118.

_ - B. Smit, and J. Wandel, 2006: Vulnerability to climate change in the Arctic: A case study from Arctic Bay, Canada. Global Environ. Change, 16, 145-160, https://doi.org/10.1016/ j.gloenvcha.2005.11.007.

, W. Vanderbilt, and L. Berrang-Ford, 2012: Authorship in IPCC AR5 and its implications for content: climate change and Indigenous populations in WGII. Climatic Change, 113, 201-213, https://doi.org/10.1007/s10584-011-0350-z.

—, L. Cameron, J. Rubis, M. Maillet, D. Nakashima, A. C. Willox, and T. Pearce, 2016: Including Indigenous knowledge and experience in IPCC assessment reports. Nat. Climate Change, 6, 349-353, https://doi.org/10.1038/nclimate2954.

García-Oliva, F., R. L. Sanford Jr., and E. Kelly, 1999: Effects of slash-and-burn management on soil aggregate organic $\mathrm{C}$ and $\mathrm{N}$ in a tropical deciduous forest. Geoderma, 88, 1-12, https:// doi.org/10.1016/S0016-7061(98)00063-9.

GIZ, 2014: A Framework for Climate Change Vulnerability Assessments. Deutsche Gesellschaft für Internationale Zusammenarbeit
(GIZ) Rep., 182 pp., https://www.adaptationcommunity.net/ ?wpfb_dl=236.

Green, D., and G. Raygorodetsky, 2010: Indigenous knowledge of a changing climate. Climatic Change, 100, 239-242, https:// doi.org/10.1007/s10584-010-9804-y.

Haasnoot, M., H. Middelkoop, A. Offermans, E. van Beek, and W. P. A. van Deursen, 2012: Exploring pathways for sustainable water management in river deltas in a changing environment. Climatic Change, 115, 795-819, https://doi.org/ 10.1007/s10584-012-0444-2.

_ , J. H. Kwakkel, W. E. Walker, and J. ter Maat, 2013: Dynamic adaptive policy pathways: A method for crafting robust decisions for a deeply uncertain world. Global Environ. Change, 23, 485498, https://doi.org/10.1016/j.gloenvcha.2012.12.006.

Hidalgo, H. G., J. A. Amador, E. J. Alfaro, and B. Quesada, 2013: Hydrological climate change projections for Central America. J. Hydrol., 495, 94-112, https://doi.org/10.1016/ j.jhydrol.2013.05.004.

Hjorth, P., and A. Bagheri, 2006: Navigating towards sustainable development: A system dynamics approach. Futures, 38, 74 92, https://doi.org/10.1016/j.futures.2005.04.005.

ILO, 2017: Indigenous peoples and climate change: From victims to agents through decent work. International Labour Office Rep., 45 pp., http://www.ilo.org/wcmsp5/ groups/public/---dgreports/---gender/documents/publication/ wcms_551189.pdf.

IPCC, 2014: Climate Change 2014: Synthesis Report. R. K. Pachauri and L. A. Meyer, Eds., IPCC, 151 pp., https://www.ipcc.ch/site/ assets/uploads/2018/02/SYR_AR5_FINAL_full.pdf.

, 2018: Summary for policymakers. Global Warming of $1.5^{\circ} \mathrm{C}: \mathrm{An}$ IPCC Special Report on the Impacts of Global Warming of $1.5^{\circ} \mathrm{C}$ above Pre-industrial Levels and Related Global Greenhouse Gas Emission Pathways, in the Context of Strengthening the Global Response to the Threat of Climate Change, Sustainable Development, and Efforts to Eradicate Poverty. V. Masson-Delmotte et al., Eds., IPCC, 1-32, https://www.ipcc.ch/site/assets/uploads/ sites/2/2018/07/SR15_SPM_version_stand_alone_LR.pdf.

Kates, R. W., and Coauthors, 2001: Sustainability science. Science, 292, 641-642, https://doi.org/10.1126/science.1059386.

Kleinman, P. J., D. Pimentel, and R. B. Bryant, 1995: The ecological sustainability of slash-and-burn agriculture. Agric. Ecosyst. Environ., 52, 235-249, https://doi.org/10.1016/01678809(94)00531-I.

— R. B. Bryant, and D. Pimentel, 1996: Assessing ecological sustainability of slash-and-burn agriculture through soil fertility indicators. Agron. J., 88, 122-127, https://doi.org/10.2134/ agronj1996.00021962008800020002x.

Leigh, E. G., Jr., D. M. Windsor, A. S. Rand, and R. B. Foster, 1990: The impact of the "El Niño" drought of 1982-83 on a Panamanian semideciduous forest. Global Ecological Consequences of the 1982-83 El Nino-Southern Oscillation, P. W. Glynn, Ed., Elsevier Oceanography Series, Vol. 52, Elsevier, 473-486, https://doi.org/10.1016/S0422-9894(08)70046-1.

Magrin, G. O., J. A. Marengo, J.-P. Boulanger, M. S. Buckeridge, E. Castellanos, G. Poveda, F. R. Scarano, and S. Vicuña, 2014: Central and South America. Climate Change 2014: Impacts, Adaptation, and Vulnerability. Part B: Regional Aspects, V. R. Barros et al., Eds., Cambridge University Press, 1499-1566.

Maldonado, J., and Coauthors, 2016: Engagement with Indigenous peoples and honoring traditional knowledge systems. Climatic Change, 135, 111-126, https://doi.org/10.1007/s10584-015-1535-7.

Maru, Y. T., M. Stafford Smith, A. Sparrow, P. F. Pinho, and O. P. Dube, 2014: A linked vulnerability and resilience framework 
for adaptation pathways in remote disadvantaged communities. Global Environ. Change, 28 (Supplement C), 337-350, https://doi.org/10.1016/j.gloenvcha.2013.12.007.

McCubbin, S., B. Smit, and T. Pearce, 2015: Where does climate fit? Vulnerability to climate change in the context of multiple stressors in Funafuti, Tuvalu. Global Environ. Change, 30, 43 55, https://doi.org/10.1016/j.gloenvcha.2014.10.007.

McDowell, N. G., and Coauthors, 2016: Multi-scale predictions of massive conifer mortality due to chronic temperature rise. Nat. Climate Change, 6, 295-300, https://doi.org/10.1038/nclimate2873.

Mearns, R., and A. Norton, 2010: Social Dimensions of Climate Change. World Bank, 319 pp.

Mendoza, G. A., and R. Prabhu, 2005: Combining participatory modeling and multi-criteria analysis for community-based forest management. For. Ecol. Manage., 207, 145-156, https://doi.org/10.1016/j.foreco.2004.10.024.

Nakashima, D. J., K. G. McLean, H. Thulstrup, A. R. Castillo, and J. T. Rubis, 2012: Weathering uncertainty: Traditional knowledge for climate change assessment and adaptation. UNESCO and United Nations University Rep., 120 pp, https://unesdoc.unesco.org/ark:/48223/pf0000216613.

Nyong, A., F. Adesina, and B. O. Elasha, 2007: The value of Indigenous knowledge in climate change mitigation and adaptation strategies in the African Sahel. Mitig. Adapt. Strategies Global Change, 12, 787-797, https://doi.org/10.1007/s11027007-9099-0.

O'Brien, K., S. Eriksen, L. P. Nygaard, and A. N. E. Schjolden, 2007: Why different interpretations of vulnerability matter in climate change discourses. Climate Policy, 7, 73-88, https:// doi.org/10.3763/cpol.2007.0706.

Padoch, C., and M. Pinedo-Vasquez, 2010: Saving slash-and-burn to save biodiversity. Biotropica, 42, 550-552, https://doi.org/ 10.1111/j.1744-7429.2010.00681.x.

Palm, C. A., and Coauthors, 1999: Carbon sequestration and trace gas emissions in slash-and-burn and alternative land-uses in the humid tropics. ICRAF Alternatives to Slash-and-Burn (ASB) Programme Rep., 39 pp., http://www.worldagroforestry.org/ downloads/Publications/PDFS/RP99031.pdf.

Pearce, T., J. Ford, A. C. Willox, and B. Smit, 2015: Inuit traditional ecological knowledge (TEK), subsistence hunting and adaptation to climate change in the Canadian Arctic. Arctic, 68, 233-245, https://doi.org/10.14430/arctic4475.

_- R. Currenti, A. Mateiwai, and B. Doran, 2018: Adaptation to climate change and freshwater resources in Vusama village, Viti Levu, Fiji. Reg. Environ. Change, 18, 501-510, https:// doi.org/10.1007/s10113-017-1222-5.

Pedroso-Junior, N. N., C. Adams, and R. S. Murrieta, 2009: Slashand-burn agriculture: A system in transformation. Current Trends in Human Ecology, Cambridge Scholars Publishing, 12-34, https://doi.org/10.5848/CSP.0441.00001.

Pelling, M., and D. Manuel-Navarrete, 2011: From resilience to transformation: The adaptive cycle in two Mexican urban centers. Ecol. Soc., 16, 11, https://doi.org/10.5751/ES-04038-160211.

Plummer, R., 2009: The adaptive co-management process: An initial synthesis of representative models and influential variables. Ecol. Soc., 14, 24, https://doi.org/10.5751/ES-03130-140224.

Purnomo, H., G. Mendoza, and R. Prabhu, 2004: Model for collaborative planning of community-managed resources based on qualitative soft systems approach. J. Trop. For. Sci., 16, 106-131, https://www.cifor.org/library/1497/.

Rauscher, S. A., F. Giorgi, N. S. Diffenbaugh, and A. Seth, 2008: Extension and intensification of the Meso-American midsummer drought in the twenty-first century. Climate Dyn., 31, 551-571, https://doi.org/10.1007/s00382-007-0359-1.

Reeder, T., and N. Ranger, 2011: How do you adapt in an uncertain world? Lessons from the Thames Estuary 2100 project. World Resources Institute Rep., 16 pp., http://wriorg.s3.amazonaws.com/ s3fs-public/uploads/wrr_reeder_and_ranger_uncertainty.pdf.

Savo, V., D. Lepofsky, J. P. Benner, K. E. Kohfeld, J. Bailey, and K. Lertzman, 2016: Observations of climate change among subsistence-oriented communities around the world. Nat. Climate Change, 6, 462-473, https://doi.org/10.1038/ nclimate2958.

Schwarz, A.-M., and Coauthors, 2011: Vulnerability and resilience of remote rural communities to shocks and global changes: Empirical analysis from Solomon Islands. Global Environ. Change, 21, 1128-1140, https://doi.org/10.1016/j.gloenvcha.2011.04.011.

Smit, B., and J. Wandel, 2006: Adaptation, adaptive capacity and vulnerability. Global Environ. Change, 16, 282-292, https:// doi.org/10.1016/j.gloenvcha.2006.03.008.

Tremblay-Boyer, L., and E. R. Anderson, 2007: Ecosystem vulnerability to climate change 1: A preliminary assessment of ecosystem vulnerability to climate change in Panama. McGill University and Smithsonian Tropical Research Institute ENVR 451-Research in Panama Rep., 70 pp., http://evccpanama.mcgill.ca/documents/EVCC_final_Nov07.pdf.

Tschakert, P., O. T. Coomes, and C. Potvin, 2007: Indigenous livelihoods, slash-and-burn agriculture, and carbon stocks in eastern Panama. Ecol. Econ., 60, 807-820, https://doi.org/ 10.1016/j.ecolecon.2006.02.001.

Turner, B. L., 2010: Vulnerability and resilience: Coalescing or paralleling approaches for sustainability science? Global Environ. Change, 20, 570-576, https://doi.org/10.1016/j.gloenvcha.2010.07.003.

— , and Coauthors, 2003: A framework for vulnerability analysis in sustainability science. Proc. Natl. Acad. Sci. USA, 100, 8074-8079, https://doi.org/10.1073/pnas.1231335100.

van Aalst, M. K., T. Cannon, and I. Burton, 2008: Community level adaptation to climate change: The potential role of participatory community risk assessment. Global Environ. Change, 18, 165-179, https://doi.org/10.1016/j.gloenvcha.2007.06.002.

Van Vliet, N., O. Mertz, T. Birch-Thomsen, and B. Schmook, 2013: Is there a continuing rationale for swidden cultivation in the 21st century? Hum. Ecol., 41, 1-5, https://doi.org/10.1007/ s10745-013-9562-3.

Vosti, S. A., and J. Witcover, 1996: Slash-and-burn agricultureHousehold perspectives. Agric. Ecosyst. Environ., 58, 23-38, https://doi.org/10.1016/0167-8809(95)00652-4.

Wickstrom, S., 2003: The politics of development in Indigenous Panama. Lat. Amer. Perspect., 30, 43-68, https://doi.org/ 10.1177/0094582X03030004006.

Wise, R., I. Fazey, M. S. Stafford Smith, S. Park, H. Eakin, E. A. Van Garderen, and B. Campbell, 2014: Reconceptualising adaptation to climate change as part of pathways of change and response. Global Environ. Change, 28, 325-336, https:// doi.org/10.1016/j.gloenvcha.2013.12.002. 